\title{
Annealing Effects on MgO Films Grown using e-beam Evaporation
}

\author{
Jitendra Pal Singh \\ Advanced Analysis Center, Korea Institute of Science and Technology, Seoul-02792, South Korea \\ ${ }^{1}$ Industrial Technology Convergence Center, Pohang Accelerator Laboratory, Pohang-37673, South Korea \\ Corresponding author: jitendra_singh2029@rediffmail.com \\ Lalit Kumar Gupta \\ Department of Applied Sciences \\ Krishna Engineering College, Ghaziabad-201007, Uttar Pradesh, India \\ (Received October 29, 2018; Accepted February 18, 2019)
}

\begin{abstract}
Present work investigates the annealing effects on $\mathrm{MgO}$ thin films deposited using e-beam evaporation method. $\mathrm{MgO}$ thin films of thickness 5 and $50 \mathrm{~nm}$ were evaporated from MgO-pellet in ultra-high vacuum $\left(2 \times 10^{-8} \mathrm{Torr}\right)$. As deposited thin films exhibit coordination similar to $\mathrm{MgO}$ bulk as envisaged from near edge $\mathrm{X}$-ray absorption fine structure measurements. As deposited films were annealed at 300,400 and $500^{\circ} \mathrm{C}$ in open environment. Thickness of films remain unaltered with annealing within experimental error. Raman spectroscopic measurements further confirm the presence of bands associated with $\mathrm{Mg}-\mathrm{O}$ bonding at such low thicknesses.
\end{abstract}

Keywords- e-beam evaporation, Annealing, Rutherford back scattering, Raman spectroscopy.

\section{Introduction}

In past few years, $\mathrm{MgO}$ has been material of great interest with the increasing demand over spintronic materials and observation of defect induced ferromagnetism (DIF). It has been seen that DIF depends upon the pre and post synthesis treatment as well as method of deposition (Singh and Chae, 2017; Pathak et al., 2017). Recent reports show the presence of unusual magnetic properties in $\mathrm{MgO}$, hence study of $\mathrm{MgO}$ is pronounced for the understanding of newly emerging field of $\mathrm{d}^{\circ}$ ferromagnetism. This motivates number of researchers to investigate this phenomenon in this material under different treatment (Ma et al., 2013; Cao et al., 2017; Qi et al., 2017).

It has also been shown experimentally that by decreasing the film thickness, enhancement/increase in magnetization can be achieved (Ma et al., 2013; Singh and Chae, 2017; Pathak et al., 2017; Cao et al., 2017; Qi et al., 2017). Deposition methods play important role in determining the properties of thin films. The properties of thin films are determined by stoichiometric proportion, lattice mismatch (Hu et al., 2010; Gazquez et al., 2013; Loureiro et al., 2014), nature of growth (Wu et al., 2014), stress developed at film substrate interface (Rao et al., 2014). Hence, number of methods are developed to deposit thin films to get control over these parameters. These methods are e-beam evaporation, pulsed laser deposition, atomic layer deposition, radio frequency sputtering method and chemical vapor deposition (Kern and Schuegraf, 2001).

\footnotetext{
${ }^{1}$ Present address
} 
International Journal of Mathematical, Engineering and Management Sciences

Vol. 4, No. 3, 619-626, 2019

https://dx.doi.org/10.33889/IJMEMS.2019.4.3-049

Near edge X-ray absorption fine structure (NEXAFS) of any material is an important tool to get information of local co-ordination, valence state of constituent ions (Singh et al., 2018a; Sharma et al., 2018). Thus, these measurements are suitable to characterize as-deposited films. Apart from deposition methods, post deposition treatment like annealing also affects the behavior of thin films. Rutherford Backscattering (RBS) spectroscopic measurements provide a way to understand the changes associated with compositional change and thickness (Singh et al., 2016). On the other hand, Raman spectroscopic measurements pave up the way to understand the changes associated with annealing on vibrational modes (Singh et al., 2011). Thus present work investigates annealing effects on e-beam evaporated $\mathrm{MgO}$ thin films using RBS and Raman spectroscopic measurements.

\section{Experimental Details}

Magnesium oxide thin films of thickness 5 and $50 \mathrm{~nm}$ were grown by e-beam evaporation method on silicon substrate. Thickness of these films was controlled using quartz crystal monitor. The substrate was kept at room temperature and deposition rate was $1 \AA$. s. The details of film deposition are published elsewhere (Singh et al., 2015). In order to investigate effect of annealing both films are annealed at 300,400 and $500^{\circ} \mathrm{C}$.

NEXAFS measurements for as-deposited films were performed at 10D XAS-KIST beamline of Pohang Accelerator Laboratory, South Korea. RBS experiments were carried out using alpha particle beam from 1.7 MV Pelletron Accelerator at Inter University Accelerator Center (IUAC), New Delhi, India. RBS simulation was done using RUMP program (Singh et al., 2016). Raman spectroscopic measurements were performed using In Via Raman microscope from Renishaw UK installed at IUAC, New Delhi. The system consists of Ar ion laser with $514.5 \mathrm{~nm}$ wavelength and $50 \mathrm{mw}$ power.

\section{Results and Discussion}

\subsection{Nature of Deposited Film}

To investigate annealing effect it is required to get information about the nature of as- deposited films. Hence, measured NEXAFS spectra of both the films are shown in Figure 1.

O $K$-edge NEXAFS spectra of both films exhibit spectral features at 538.2, 540.2, 546, 5, 553.6 and $556.9 \mathrm{eV}$ in post edge region (Singh et al., 2017). The observed spectral features in post-edge region are characteristics of $\mathrm{MgO}$ and reported by number of researchers for $\mathrm{MgO}$ thin films and nanoparticles. For these films, pre-edge spectral features appears at $533.3 \mathrm{eV}$ which is reported for ultrathin films (Luches et al., 2004; Linder et al., 2006; Singh et al., 2018b). Thus, NEXAFS measurements reveals formation of well-coordinated $\mathrm{MgO}$ thin films. To further reveal the annealing effects on these films, RBS and Raman spectroscopic measurements were performed and discussed in next section. 
International Journal of Mathematical, Engineering and Management Sciences

Vol. 4, No. 3, 619-626, 2019

https://dx.doi.org/10.33889/IJMEMS.2019.4.3-049

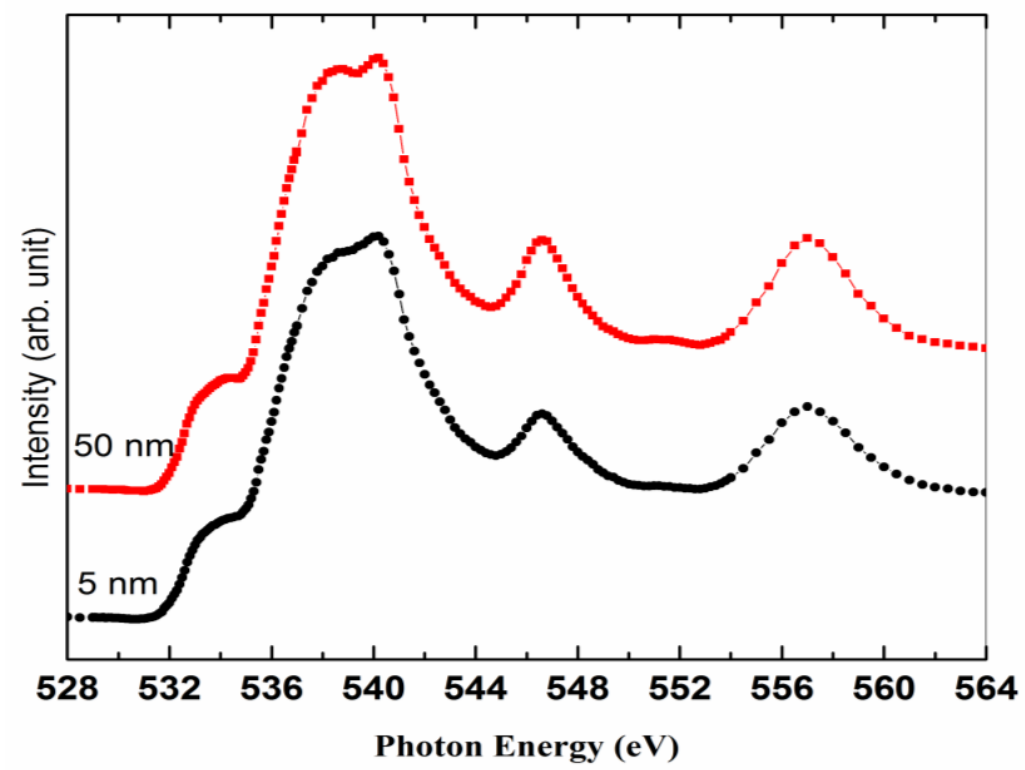

Figure 1. O K-edge NEXAFS spectra of MgO thin films of thicknesses 5 and $50 \mathrm{~nm}$.

\subsection{Annealing Effects}

\subsubsection{RBS Spectroscopy Study}

Table 1 shows the parameters used for simulation of this film. Table 1 shows composition and thickness of these films at various annealing temperature. It is clear that thickness of as-grown film is $5 \mathrm{~nm}$ and remain unaltered with increase of annealing temperature. Moreover, composition also remain same with annealing.

Table 1. Parameters estimated from RBS simulation of $\mathrm{MgO}$ film of thickness $5 \mathrm{~nm}$. Layer 1 and layer 2 correspond to $\mathrm{MgO}$ layer and $\mathrm{Si}$ substrate

\begin{tabular}{|c|c|c|c|}
\hline Annealing Temperature $\left({ }^{\circ} \mathbf{C}\right)$ & Layers & Composition & Thickness (nm) \\
\hline \multirow{2}{*}{ As-grown } & & $\mathrm{Mg}_{0.5} \mathrm{O}_{0.5}$ & 5 \\
\cline { 2 - 4 } & 2 & $\mathrm{Si}$ & 5000 \\
\hline \multirow{2}{*}{300} & 1 & $\mathrm{Mg}_{0.5} \mathrm{O}_{0.5}$ & 5 \\
\hline & 2 & $\mathrm{Si}$ & 5 \\
\hline \multirow{2}{*}{400} & 1 & $\mathrm{Mg}_{0.5} \mathrm{O}_{0.5}$ & 5000 \\
\cline { 2 - 4 } & 2 & $\mathrm{Si}$ & 5 \\
\hline \multirow{2}{*}{500} & 1 & $\mathrm{Mg}_{0.47} \mathrm{O}_{0.53}$ & 5000 \\
\hline
\end{tabular}

Figure 2 shows RBS spectra of film grown for film thickness of $5 \mathrm{~nm}$. At a glance, it appears that there are no $\mathrm{Mg}^{2+}$ and $\mathrm{O}^{2-}$ on the surface of $\mathrm{Si}$, however, $\mathrm{O} K$-edge spectrum clearly reveals the presence of $\mathrm{MgO}$ (Figure 1). It is contemplated that $\mathrm{Mg}^{2+}$ and $\mathrm{O}^{2-}$ ions can't be detected by $\mathrm{RBS}$ measurements due to low thickness of the films. 
International Journal of Mathematical, Engineering and Management Sciences

Vol. 4, No. 3, 619-626, 2019

https://dx.doi.org/10.33889/IJMEMS.2019.4.3-049
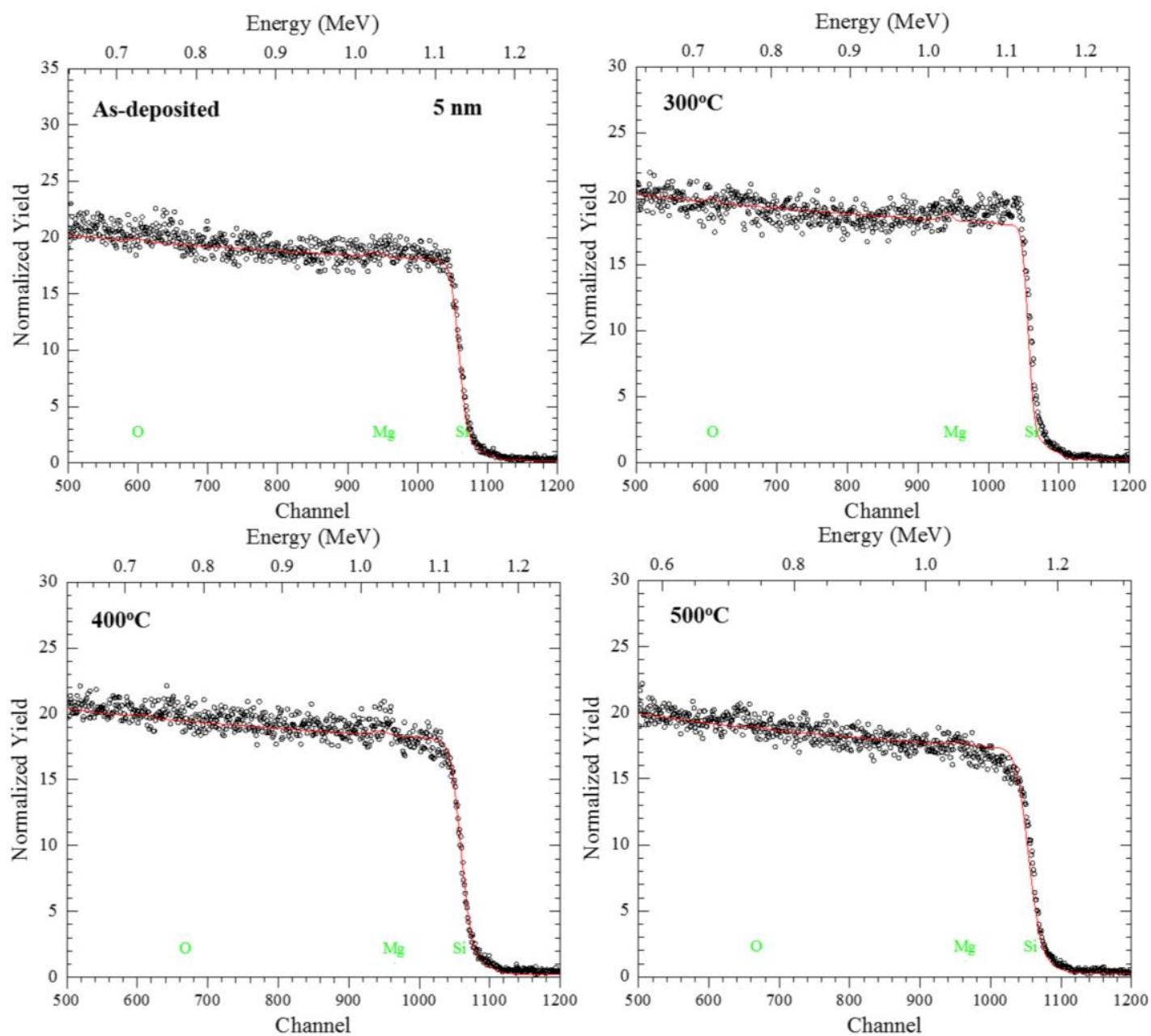

Figure 2. Experimental (open circles) and simulated (red line) RBS spectra of as-deposited thin film of thickness $5 \mathrm{~nm}$ annealed at 300,400 and $500^{\circ} \mathrm{C}$

Figure 3 shows RBS spectra of as-grown film of thickness of $50 \mathrm{~nm}$ at various annealing temperature. RBS spectra of $\mathrm{MgO}$ thin films exhibit spectral features corresponding to $\mathrm{Mg}^{2+}$ and $\mathrm{O}^{2-}$ ions. Thickness of as-grown film is $102 \mathrm{~nm}$ as determined from RBS simulation. This value of thickness is almost double from that determined from quartz crystal monitor. Composition of as-grown thin film is $\mathrm{Mg}_{0.5} \mathrm{O}_{0.5}$. Composition modifies slightly with annealing (Table 2). Since, it is thick layer, hence, it is expected that a significant amount of $\mathrm{Mg}^{2+}$ and $\mathrm{O}^{2-}$ ions will diffuse into $\mathrm{Si}$, hence, a diffused layer (Layer 2 in Table 2 ) is also considered during simulation. Composition of both $\mathrm{MgO}$ layer as well as diffused layer modifies significantly. Table 2 shows a variation of thickness of $\mathrm{MgO}$ film which is associated with depth resolution of RBS technique. 
International Journal of Mathematical, Engineering and Management Sciences

Vol. 4, No. 3, 619-626, 2019

https://dx.doi.org/10.33889/IJMEMS.2019.4.3-049
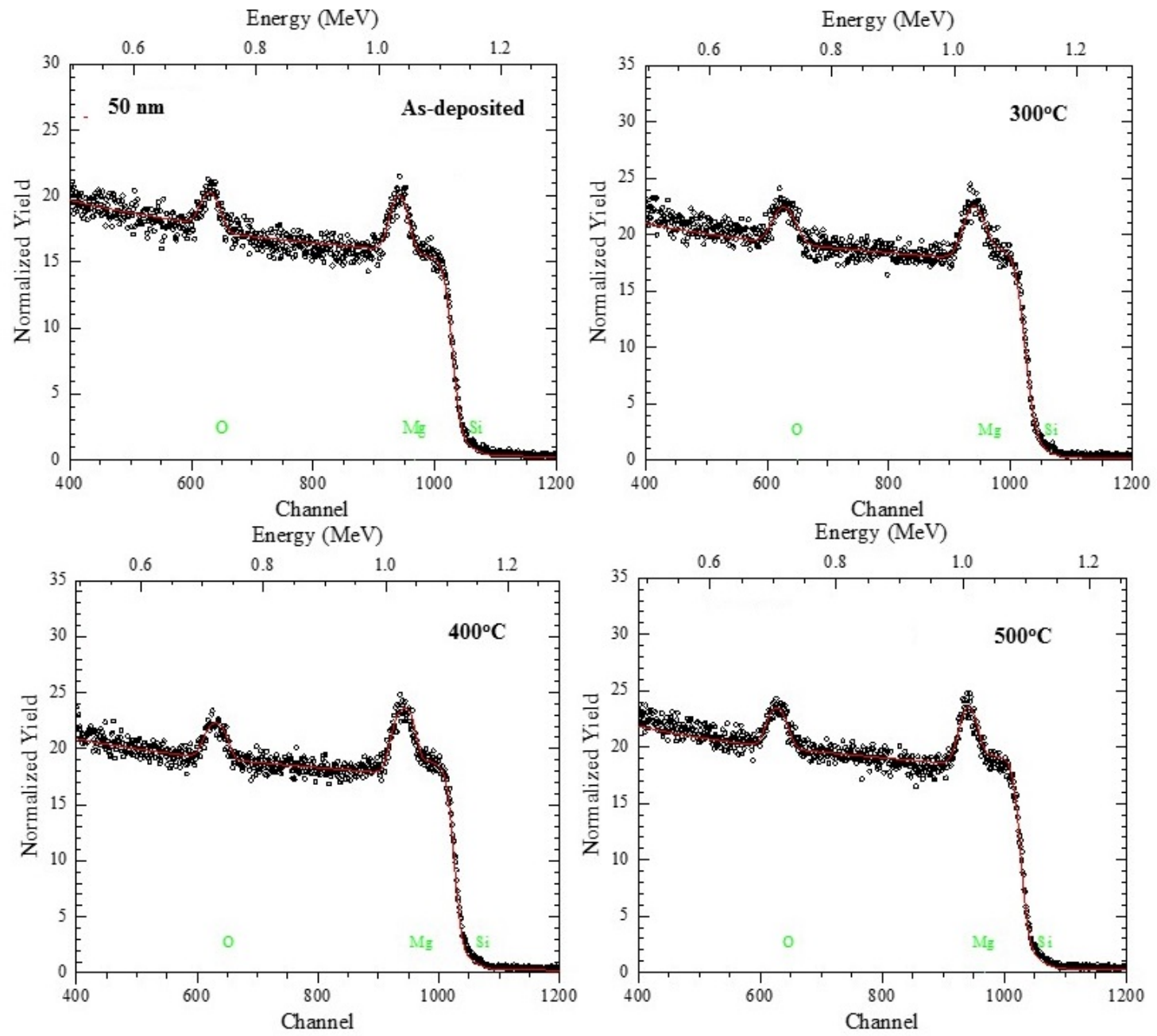

Figure 3. Experimental (open circles) and simulated (red line) RBS spectra of as-deposited thin film of thickness $50 \mathrm{~nm}$ annealed at 300,400 and $500^{\circ} \mathrm{C}$.

Table 2. Parameters estimated from RBS simulation of $\mathrm{MgO}$ film of thickness $50 \mathrm{~nm}$. Layer 1, Layer 2 and Layer 3 are corresponding to $\mathrm{MgO}$ layer, diffused layer and Si substrate

\begin{tabular}{|l|c|c|c|}
\hline Annealing Temperature $\left({ }^{\circ} \mathbf{C}\right)$ & Layers & Composition & Thickness (nm) \\
\hline \multirow{3}{*}{ As-grown } & & $\mathrm{Mg}_{0.5} \mathrm{O}_{0.5}$ & 109 \\
\hline \multirow{3}{*}{300} & 1 & $\mathrm{Mg}_{0.04} \mathrm{O}_{0.04} \mathrm{Si}_{0.32}$ & 10 \\
\cline { 2 - 4 } & 3 & $\mathrm{Si}$ & 5000 \\
\cline { 2 - 4 } & 1 & $\mathrm{Mg}_{0.46} \mathrm{O}_{0.54}$ & 120 \\
\cline { 2 - 4 } & 2 & $\mathrm{Mg}_{0.04} \mathrm{O}_{0.04} \mathrm{Si}_{0.33}$ & 5000 \\
\cline { 2 - 4 } & 3 & $\mathrm{Si}$ & 30 \\
\hline \multirow{3}{*}{500} & 1 & $\mathrm{Mg}_{0.5} \mathrm{O}_{0.5}$ & 5000 \\
\cline { 2 - 4 } & 2 & $\mathrm{Mg}_{0.06} \mathrm{O}_{0.04} \mathrm{Si}_{0.5}$ & 103 \\
\cline { 2 - 4 } & 3 & $\mathrm{Si}_{0.46} \mathrm{O}_{0.54}$ & 22 \\
\hline
\end{tabular}


International Journal of Mathematical, Engineering and Management Sciences

Vol. 4, No. 3, 619-626, 2019

https://dx.doi.org/10.33889/IJMEMS.2019.4.3-049

\subsubsection{Raman Spectroscopic Measurements}

Figure 4 shows the Raman spectra for as-grown and annealed thin films having thickness $50 \mathrm{~nm}$. In the spectra of these films two small bands appears at $970 \mathrm{~cm}^{-1}$ and $1122 \mathrm{~cm}^{-1}$ apart from intense band at $518 \mathrm{~cm}^{-1}$. The intense band at $518 \mathrm{~cm}^{-1}$ is due to Si substrate (Parker et al., 1967). The band appearing at $970 \mathrm{~cm}^{-1}$ is associated with second order Raman band present in Si (Meier et al., 2006).

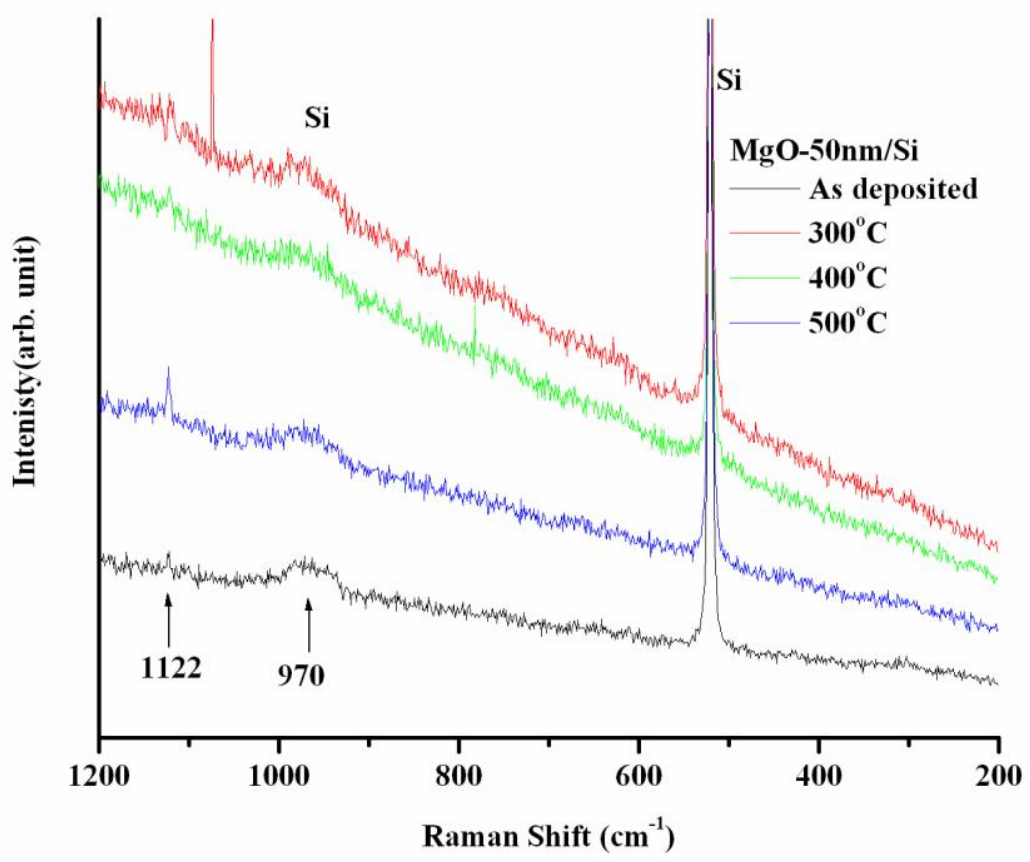

Figure 4. Raman spectra of as deposited $\mathrm{MgO}$ films of thickness $50 \mathrm{~nm}$ at 300,400 and $500^{\circ} \mathrm{C}$

In the spectrum of $\mathrm{MgO}$, second order Raman bands appears around $1088 \mathrm{~cm}^{-1}$ (Meier et al., 2006). In our case, band around $1122 \mathrm{~cm}^{-1}$ may be associated with second order Raman band in MgO (Manson et al., 1971; Schlecht et al., 1973).

\section{Conclusion}

In conclusion, $\mathrm{MgO}$ thin films of thickness 5 and $50 \mathrm{~nm}$ were grown using e-beam evaporation method. $\mathrm{O} K$-edge near edge $\mathrm{X}$-ray absorption fine structure measurements revealed local electronic structure analogues to bulk MgO. RBS measurements reflect no change of thickness within experimental error after annealing. Raman measurements show occurrence of Raman bands at such low thickness. 
International Journal of Mathematical, Engineering and Management Sciences

Vol. 4, No. 3, 619-626, 2019

https://dx.doi.org/10.33889/IJMEMS.2019.4.3-049

\section{Conflicts of Interests}

The authors confirm that this article contents have no conflict of interest.

\section{Acknowledgments}

JPS is thankful to Dr. D. Karibaj, Mr. Sunil Ojha and Dr. Foran Singh, Inter-University Accelerator Center, New Delhi, India for providing access to e-beam evaporation facility, X-ray diffraction, RBS spectrometer and Raman spectrometer for growing and characterization of these films. JPS is also thankful to Dr. K. Asokan, Inter University Accelerator Center, New Delhi and Prof. Keun Hwa Chae for fruitful discussion during the implementation of this work.

\section{References}

Cao, M., Ma, Y., Wang, X., Ma, C., Zhou, W., Wang, X., Tan, W., \& Du, J. (2017). Point defects and magnetic properties of neutron irradiated $\mathrm{MgO}$ single crystal. AIP Advances, 7(5), 056413

Gazquez, J., Bose, S., Sharma, M., Torija, M.A., Pennycook, S.J., Leighton, C., \& Varela, M. (2013). Lattice mismatch accommodation via oxygen vacancy ordering in epitaxial $\mathrm{La}_{0.5} \mathrm{Sr}_{0.5} \mathrm{CoO}_{3-\delta}$ thin films APL Materials, 1(1), 012105-1-7.

Hu, L., Hecht, D.S., \& Gruner, G. (2010). Carbon nanotube thin films: fabrication, properties, and applications. Chemical Reviews, 110(10), 5790-5844.

Kern, W., \& Schuegraf, K.K. (2001). Deposition technologies and applications: introduction and overview. In: Krisna Seshan (ed.), Handbook of Thin Film Deposition Processes and Techniques (2 ${ }^{\text {nd }}$ Edition), William Andrew Publishing (pp. 11-43). Elsevier

Linder, T., Sauer, H., Engel, W., \& Kmabe, K. (2006). Near-edge structure in electron-energy-loss spectra of MgO. Physical Review B, 33(1), 22-24

Loureiro, J., Santos, J.R., Nogueira, A., Wyszisk, F., Divay, L., Reparaz, S., Alzina, F., Torres, C.L.M., Cuffee, J., Montemor, F., Martinsa, R., \& Ferreira, I. (2014) Nanostructured p-type $\mathrm{Cr} / \mathrm{V}_{2} \mathrm{O}_{5}$ thin films with boosted thermoelectric properties. Journal of Materials Chemistry A, 2(18), 6456-6462.

Luches, P., D’Addato, S., Valeri, S., Groppo, E., Prestipino, C., Lamberti, C., \& Boscherini, F. (2004). Xray absorption study at the $\mathrm{Mg}$ and $\mathrm{O} \mathrm{K}$ edges of ultrathin $\mathrm{MgO}$ epilayers on $\mathrm{Ag}$ (001). Physical Review B, 69(4), 045412.

Ma, C., Liu, M., Chen, C., Lin, Y.; Li, Y., Horwitz, J.S., Jiang, J., Meletis, E.I., \& Zhang, Q. (2013). The origin of local strain in highly epitaxial oxide thin films. Scientific Reports, 3, 3092-1-5

Manson, N.B., Von der Ohe, W., \& Chodos, S.L. (1971). Second-order Raman spectrum of MgO. Physical Review $B, 3(6), 1968$.

Meier, C., Lüttjohann, S., Kravets, V.G., Nienhaus, H., Lorke, A., \& Wiggers, H. (2006). Raman properties of silicon nanoparticles. Physica E: Low-Dimensional Systems and Nanostructures, 32(1-2), 155-158.

Parker Jr, J.H., Feldman, D.W., \& Ashkin, M. (1967). Raman scattering by silicon and germanium. Physical Review, 155(3), 712-714

Pathak, N., Gupta, S.K., Prajapat, C.L., Sharma, S.K., Ghosh, P.S., Kanrar, B., Pujari, P.K., \& Kadam, R.M. (2017). Defect induced ferromagnetism in $\mathrm{MgO}$ and its exceptional enhancement upon thermal annealing: a case of transformation of various defect states. Physical Chemistry Chemical Physics, 19(19), 11975-11989.

Qi, L.Q., Liu, L.H., Feng, S.Z., Sun, H.Y., \& Han, R.S. (2017). Synthesis and magnetic properties of ceramic MgO porous film. Journal of the European Ceramic Society, 37(15), 4727-4731. 
International Journal of Mathematical, Engineering and Management Sciences

Vol. 4, No. 3, 619-626, 2019

https://dx.doi.org/10.33889/IJMEMS.2019.4.3-049

Rao, A., Dsa, J., Goyal, S., \& Singh, B.R. (2014). Stress induced degradation in sputtered ZrO2 thin films on Silicon for Nano-MOSFET's. In: Jain, V., \& Verma, A. (eds) Physics of Semiconductor Devices. Environmental Science and Engineering. (pp 555-558), Springer, Cham.

Schlecht, R.G., \& Böckelmann, H.K. (1973). Raman scattering from microcrystals of MgO. Physical Review Letters, 31(15), 930-932.

Sharma, A., Singh, J.P., Won, S.O., Chae, K.H., Sharma, S.K., \& Kumar, S. (2018). Introduction to X-Ray Absorption Spectroscopy and its applications in material science. In Handbook of Materials Characterization (pp. 497-548). Springer, Cham.

Singh, J.P., Chen, C.L., Dong, C.L., Prakash, J., Kabiraj, J. Kanjilal, D., Pong, W.F., \& Asokan, K. (2015). Role of surface and subsurface defects in $\mathrm{MgO}$ thin film: XANES and magnetic investigations. Superlattices and Microstructures, 77, 313-324.

Singh, J.P., \& Chae, K. H. (2017). d ${ }^{\circ}$ Ferromagnetism of Magnesium Oxide. Condensed Matter, 2 (4), 36.

Singh, J.P., Kaur, B., Sharma, A., Kim, S.H., Gautam, S., Srivastava, R.C., Goyal, N., Lim, W.C., Lin, HJ., Chen, J.M., Asokan, K., Kanjilal, D., Won, S.O., Lee, I.J., Chae, K.H. (2018a). Mechanistic insights into the interaction between energetic oxygen ions and nanosized $\mathrm{ZnFe}_{2} \mathrm{O}_{4}$ : XAS-XMCD investigations. Physical Chemistry Chemical Physics, 20(17), 12084-12096.

Singh, J.P., Kumar, M., Lee, I.J., \& Chae, K.H. (2017). X-ray reflectivity and near edge X-ray absorption fine structure investigations of $\mathrm{MgO}$ thin films. Applied Science Letters, 3(3), 47-52

Singh, J.P., Lim, W.C., \& Chae, K.H (2016). Atomic diffusion processes in $\mathrm{MgO} / \mathrm{Fe} / \mathrm{MgO}$ multilayer. Superlattices and Microstructures, 88(12), 609-619

Singh, J.P., Lim, W.C., Lee, I.J., Won, S.O., \& Chae, K.H. (2018b). Surface Structure of MgO Thin Films Revealed from X-ray reflectivity and near-edge X-ray absorption fine structure measurements. Science of Advanced Materials, 10(9), 1372-1376.

Singh, J.P., Srivastava, R.C., Agrawal, H.M., \& Kumar, R. (2011). Micro-Raman investigation of nanosized zinc ferrite: effect of crystallite size and fluence of irradiation. Journal of Raman Spectroscopy, 42(7), 1510-1517.

Wu, H.-C., Mauit, O., Ó Coileáin, C., Syrlybekov, A., Khalid, A., Mouti, A., Abid, M., Zhang, H.-Z., Abid M., \& Shvets, I. V. (2014). Magnetic and transport properties of epitaxial thin film $\mathrm{MgFe}_{2} \mathrm{O}_{4}$ grown on $\mathrm{MgO}$ (100) by molecular beam epitaxy. Scientific Reports, 4, 7012-1-6. 